\title{
How sWOM Contribution Motivations Vary by Cosmetics and Restaurants in Vietnam*
}

\author{
Thi Thanh Ha LE', Thanh Thu VO²
}

Received: August 01, 2020 Revised: September 06, 2020 Accepted: September 10, 2020

\begin{abstract}
The purpose of this study is to shed light on the driving motivations of contributing social word of mouth on social networking sites (sWOM) toward both tangible and intangible products. In order to develop a research model, this study adopts the motivation theory and TAM model. Data was collected from 904 members of the cosmetic and restaurant communities by using the snowball method. After assessing the validity of all constructs, the structural equation modeling (SEM) is used to test the proposed hypotheses. Results show that personal motivations (satisfaction, opinion leadership, self-enhancement, and economic incentives) and characteristics of sWOM (Perceived Usefulness and Ease of Use) have positive effect on exposure and engagement behaviors. Here are our specific findings, (1) customer satisfaction positively affects online interactions on SNSs such as Like or Sharing a content; (2) sWOM contribution behavior exists in two structures (Exposure and Engagement) and affects each other; (3) This study combines two groups of personal motivation and TAM to conceptualize a research model; and (4) The motivations of contributing sWOM between a specified service and product are rather similar. These findings help digital managers to understand consumers' behavioral contributions on SNSs and also provide interesting insights for marketers.
\end{abstract}

Keywords: sWOM Contribution, Opinion Leadership, Self-Enhancement, Economic Incentives, Technology Acceptance Model

JEL Classification Code: L81, L83, M31, M37, M39

\section{Introduction}

Social network sites (SNSs) such as Facebook, Instagram or Twitter allow people to perform several actions like sharing and passing photos, videos, and statements with

\footnotetext{
*Acknowledgements:

We hereby confirm that the manuscript has no actual or potential conflict of interest with any parties, including any financial, personal or other relationships with other people or organizations within 3 years of initiation or submission of work that could be inappropriately influenced or be perceived to influence this work. We confirm that the paper has not been published previously, it is not under consideration for publication elsewhere, and the manuscript is not being simultaneously submitted elsewhere.

${ }^{1}$ First Author and Corresponding Author. Lecturer, Faculty of Business Administration, Ho Chi Minh City University of Food Industry, Ho Chi Minh City, Vietnam [Postal Address: 140 Le Trong Tan Street, Tay Thanh Ward, Tan Phu District, Ho Chi Minh City, 72009, Vietnam] Email: haltt@hufi.edu.vn

${ }^{2}$ Professor, Faculty of International Business and Marketing, University of Economics Ho Chi Minh City, Vietnam.

Email: vothanhthu@ueh.edu.vn

(c) Copyright: The Author(s)

This is an Open Access article distributed under the terms of the Creative Commons Attribution Non-Commercial License (https://creativecommons.org/licenses/by-nc/4.0/) which permits unrestricted non-commercial use, distribution, and reproduction in any medium, provided the original work is properly cited.
}

others (Lee, 2017; Gvili \& Levy, 2018) called sWOM (Eisingerich, Chun, Liu, Jia, \& Bell, 2015). sWOM is a particular form of eWOM, performing online social interactions like sharing and contributing product reviews could be rapidly spread among online shoppers within SNSs (Eisingerich et. al., 2015). Compared with eWOM, sWOM has many comparative advantages of credibility because of defined online users (Balaji, Khong \& Chong, 2016) so sWOM is becoming a very popular tool for digital marketing campaigns. Yet there is little study which focusses on sWOM behavior on SNS. Exploration of existing sWOM theoretical frameworks, there are two directions of conceptualizing sWOM. They are (1) sWOM consumption: customer as an audience who reads eWOM/sWOM to get a tour (Litvin, Goldsmith \& Pan, 2008), buy online products (Tsao, 2019), or visit a restaurant (Oliveira \& Casais, 2019); and (2) sWOM contribution: customer as a sender or contributor, including activities of creating and spreading sWOM such as like, share or pass product news (Rossmann, Ranjan \& Sugathan 2016).

While the sWOM consumption has received much attention, the literature on sWOM contribution is relatively less developed. Each previous researcher has examined sWOM contribution in different types, such as forwarding (Doma, 
Elaref \& Elnaga, 2015); Write a content (Kim, Jang \& Adler, 2015); Comment or Reply (Muntinga, Moorman \& Smit, 2011); Share (Park \& Kang, 2013); become a Fan (Ruiz-Mafe, Martí-Parreño, \& Sanz-Blas, 2014); Follow (Casaló, Flavián \& Ibáñez-Sánchez, 2017). Likes, Visits or Views usually need less effort than comment, share or forwarding (Rossmann, et. al., 2016). In addition, online customers not only perform a single behavior but also a combination of many types. From the perspective of online communication effectiveness, each type will bring a different result of social media measurement. The sWOM contribution activities have but remained fully unexplored, it is expected that the present research proposes a comprehensive sWOM contribution scales.

Both Facebook and YouTube in Vietnam have about 6.5 millions of users, and has penetrated $67 \%$ of total population (Kemp, 2020). The high growth of Vietnamese social media active users has driven the online marketers to focus on SNSs. Cosmetics and restaurants are main topics which are largely discussed on SNS in Vietnam. As the competition has become progressively stiffer, Vietnamese cosmetics and restaurants businesses are actively conducting digital marketing programs to gain positive recommendations from followers or fans. Taking these into consideration, this research aims to consider consumer information spread and its effect on behaviors on SNS concerning the cosmetic and restaurant industries. First, we provide the comprehensive understanding of sWOM contribution behavior by offering different constructs. Second, we offer a complex set of motives which marketers facilitate consumers to actively and positively communicate sWOM over social media. Finally, digital managers need to understand what differences in motives and strategies to engage cosmetic and restaurant customers.

\section{Theoretical Background and Hypotheses}

\section{1. sWOM Contribution}

Sharing or posting daily activities on SNSs has now become a trend. SNSs such as Facebook, Instagram and YouTube are popular platforms for customers for sharing their experiences and opinions, because they facilitate consumers' participation actively in the online communication process. In this study, sWOM, is often referred to as online news sharing, online opinions posting and online videos or photos uploading, is actively created in SNSs by registered users. Marketers are facing many challenges when they attempt to set a strong relationship with their online communities by encouraging customers to engage and participate in contributing sWOM. Dolan, Conduit, Frethey-Bentham, Fahy \& Goodman (2019) conceptualized that the contributing action is of a moderate level of positive and active activities which include Liking and
Sharing company brands to customers' social media profiles. Ananda, Hernández-García, Acquila-Natale \& Lamberti (2019) suggest eWOM engagement on social networks include a range of interactive behaviors such as: Like, Share and Comment. These online behaviors involve using plugins which are differently designed by each SNS supplier. Consequently, sWOM contribution behavior is a set of multiple activities in which customers engage toward brand-related products or services on SNSs. In this study, we classify sWOM behavior into two general behavioral manifestations, including likes (called exposure) and comments (called engagement) about the online contents posted on SNSs (Rossmann et. al., 2016).

Previous studies postulate that consumers are encouraged to contribute sWOM by two main groups of factors: (1) characteristics of sWOM and (2) Motives. Specifically, due to the nature of sWOM is technology so TAM (technology acceptance model - a psychology-based research model) which should be used in explaining customers' acceptance of contributing sWOM. Substantial empirical researches applied TAM to explain the process of creating sWOM, example Ruiz-Mafe et. al. (2014) willing to be a fan of a brand on Facebook; Doma et. al., (2015) emphasized the perceived usefulness and perceived ease of use of eWOM affecting to write comments on Facebook; Casaló et. al., (2017) focused on TAM for explaining consumers to Follow or Recommend on Instagram. Concerning motive group, Hennig-Thurau, Gwinner, Walsh \& Gremler (2004) predicted such motives: venting negative feelings, concern for other consumers, social benefit, economic incentives. Subsequently, recent studies added different motivations such as opinion leadership (Ma, Lee \& Goh 2014; Kim et. al., 2015; Styvén \& Foster, 2018); social benefits (Gvili \& Levy, 2018); narcissism or reflected appraisal of self (Park \& Kang, 2013; Kim et. al., 2015; Belarmino \& Koh, 2018; Styvén \& Foster, 2018). To date, very few papers pay attention to combine two groups of previous factors to examine why shoppers are actively spreading sWOM on SNSs.

\subsection{Hypotheses and Research Model}

\subsubsection{Satisfaction and sWOM Contribution}

In relation to WOM - generating factors, most of the recent studies have mentioned aspects of customer satisfaction as consumers' main drivers for WOM interaction, particularly, positive WOM (Sung, Kim \& Youn, 2014; Nguyen, Dang\&Ngo, 2019; Han, 2020). Prior studies have found empirical support on customer satisfaction and the intention of eWOM generation in service context (Yang, 2017; SerraCantallops, Ramon-Cardona \& Salvi, 2018).

The notable relationship between customer satisfaction and $\mathrm{WOM} / \mathrm{eWOM}$ communication is well-deserved for an 
extensive number of studies examines. Therefore, satisfaction may be also considered a significant factor related to the generation of sWOM contributions. Moreover, when conducting Netnography qualitative research, we discovered that if customers are satisfied with their purchased products, they are willing to participate in writing online reviews on different social media platforms. These keywords are usually mentioned such as "satisfied and want to share" and/or "make the right decision so he/she devotes his/her experiences". Thus, customers who are more satisfied with the product or service, are likely to become the main contributors of sWOM. Based on the previous reasoning, the following hypothesis are suggested:

H1a: Customer satisfaction has a positive and direct effect on sWOM contribution - Exposure.

H1b: Customer satisfaction has a positive and direct effect on sWOM contribution - Engagement.

\subsubsection{Opinion Leadership and sWOM Contribution}

Customers who posess characteristics of opinion leaders, have the skills and ability to influence other individuals' attitudes or behaviors in several ways (Styvén \& Foster, 2018). Flynn, Goldsmith \& Eastman (1996) stated that opinion leadership customers directly influence others in different ways by giving advice or spreading information, are called as the originators in WOM communications. Previously, Summers (1970) carried out a comparison between individuals who are opinion leaders and who are not, the results confirmed that there are influential customers who regularly receive and forward information to others.

Based on the diffusion of innovations theory, Ma et. al. (2014) suggested that opinion leaders are innovative in sharing messages and influencing others in an informanl manner. He stated that opinion leaders in SNSs have a very large number of followers and friends or subscribers, the extent of spread of reviews is significantly widened if they are engaged in sharing news. Consumers tend to share their experiences with others on social media platforms, reflecting on how they want to be seen by their online communities (Eastman, Iyer, Liao-Troth, Williams \& Griffin, 2014). In other words, opinion leaders are more likely to contribute their stories and photos on social media. Kim et. al. (2015) also argued that motivations of eWOM intentions depend on the level of opinion leadership possessed by online customers. Thus, we expect that consumers who are opinion leaders may act as informants by performing exposure and engagement activities.

H2a: Opinion leadership has a positive and direct effect on sWOM contribution - Exposure.

H2b: Opinion leadership has a positive and direct effect on sWOM contribution - Engagement.

\subsubsection{Self-Enhancement and sWOM Contribution}

Sundaram, Mitra, \& Webster (1998) demonstrated that the self-enhancement motive is to gain attention from other friends and relatives. He stressed individuals are likely to spread their positive experiences by sharing WOM in an effort to enhance their self-image and show themselves as intelligent customers among others. Based on the Sundaram's literature, Hennig-Thurau et. al., (2004) have identified the self-enhancement motive is a consumer need which can be satisfied through electronic communication. Because of the large reach and extent of eWOM, it allows customers to gain recognition, show connoisseurship, and get impressions that can become important to one's self-perception.

Previously, researchers have found a significant relationship between self-enhancement and eWOM. Because individuals tend to engage in self-enhancement, they publicly present their consumption experiences to others via eWOM (Kim et. al., 2015). With an underlying desire to be positively recognized as an expert by others, these typrs of consumers are more likely to post on the company website (Belarmino \& Koh, 2018). The desire of gaining positive attention from online communities can be a part of the motivation for travelers to share their travel experiences on the social media (Styvén \& Foster, 2018). From the above explanation, it can be argued that high self-enhancement individuals use both types of sWOM communications to increase their selfimage on social media platforms. We propose the following hypothesis:

\section{H3a: Self-enhancement has a positive and direct effect on sWOM contribution - Exposure. \\ H3b: Self-enhancement has a positive and direct effect on sWOM contribution - Engagement.}

\subsubsection{Satisfaction, Self-Enhancement and Opinion Leadership}

Lyons \& Henderson (2005) describe opinion leaders who have excellent experiences and expert knowledge about the product categories, have frequently collected more information about the product. Jungnickel (2018) emphasizes that several characteristics useful in identifying online opinion leaders can be described by their competence and knowledge. The knowledge related to products which opinion leaders acquire come from their consumption experiences. Often, satisfied customers are more likely to raise self-relevant value than non-satisfied customers. Choosing a cafe shop occurs when products are consistent with a consumer's self-image (Kim et. al., 2015), in turn, their consumption satisfaction likely leads to a selfenhancement motive. Styvén \& Foster (2018) has also found 
that self-concept is an antecedent to opinion leadership. He also confirms that self-enhancement positively relates to opinion leadership. From the above review, the following hypotheses are suggested:

H4: Satisfaction has a positive direct and effect on Opinion leadership

H5: Satisfaction has a positive direct and effect on Selfenhancement

H6: Self-enhancement has a positive and direct effect on Opinion leadership

\subsubsection{Economic Incentives and SWOM Contribution}

Economic incentives have been demonstrated to be a critical motivation of human behavior in general (Blau, 1964) and are defined as rewards for eWOM communication from Web-based platform operators (Hennig-Thurau et al., 2004). These characteristics of eWOM communication make them different from traditional WOM communication. HennigThurau et al., (2004) highlighted that contributors recognized economic rewards as the highest motivation among the four groups. On the Internet, writing and sharing on online platforms may allow customers to gain more financial rewards (Bronner \& De Hoog, 2011). Similarly, individuals regularly aim at economic returns for sharing positive eWOM in online review platforms with others. In addition, financial benefits have significant indirect and total effects on eWOM on SNSs (Doma et. al., 2015). Today, online platform operators encourage their users to upload and create online content by adding a set of smart tools and advertise that they can make money based on their photos or video uploaded. Thus, customers are financially motivated toward earning throughout their contribution activities such as Like and Share. Accordingly, the proposed hypotheses are:

H7a: Economic incentives has a positive and direct effect on sWOM contribution - Exposure.

H7b: Economic incentives has a positive and direct effect on sWOM contribution - Engagement.

\subsubsection{Perceived Ease of Use (PEU), Perceived Usefulness (PU) and SWOM Contribution}

Based on our review of existing sWOM literature, characteristics SWOM are differently validated depending on the research lines. For the line of sWOM consumption, sWOM are normally characterized for their credibility, timeliness, accuracy or comprehensiveness which directly makes an impact on their purchase planning and decisions (Tan \& Lee, 2019). On another line, two constructs of TAM model include the perceived usefulness and perceived ease of sWOM which have been successfully explained for sWOM contribution activities (Doma, et. al., 2015; Casaló et. al., 2017). In this paper, we apply TAM model in explaining what online customers voluntarily contribute sWOM on social media sites.

Perceived usefulness (PU) refers to the use of a particular technology to enhance performance of tasks (Davis, 1989) which, in the SNS context, is related to use a specific SNS or spread useful knowledge on SNSs that helps to meet the related goal-driven needs of the contributor (Casaló et. al., 2017; Rauniar, Rawski, Yang \& Johnson, 2014). Each SNS platform offers various types of tools and plugins for users to be able to obtain and share information about a specific topic of interest in a convenient and quick way. Seol, Lee, Yu, \& Zo (2016) suggest that perceived usefulness is considered an important antecedent of continuous engagement of corporate SNS pages. Moreover, users will continually engage and contribute to social-media-related activities only if they receive perceived usefulness from such contribution behaviors (Rauniar et. al., 2014). Therefore, perceived usefulness allows SNS users to catch up on online interaction.

Social media have become an indispensable part of everyday life for people all over the world. It is not surprising that SNSs have been able to attract over 3.80 billion users worldwide (Kemp, 2020) because people easily and quickly create online social accounts and enjoy these services (Rauniar et. al., 2014). The concept of perceived ease of use relates to the degree of sWOM activities on SNS that takes minimal effort to contribute (Davis, 1989). Today, SNS platforms allow users to take the least effort required to customize individual profiles, integrate with other platforms, perform various tasks, and contribute sWOM activities, such as posting content, uploading, and sharing clips (Rauniar et. al., 2014). Several recent studies have populated that the perceived ease of use of eWOM on SNS is a positive direct effect on eWOM engagement (Doma et. al., 2015). Based on TAM, we propose the four following hypothesis:

H8a: Perceived usefulness has a positive and direct effect on sWOM contribution - Exposure.

H8b: Perceived usefulness has a positive and direct effect on sWOM contribution - Engagement.

H9a: Perceived Ease of Use has a positive and direct effect on sWOM contribution - Exposure.

H9b: Perceived Ease of Use has a positive and direct effect on sWOM contribution - Engagement.

Two structures of TAM model not only directly involve in sWOM communication (Doma et. al., 2015; Rauniar et. al., 2014; Ruiz-Mafe et. al., 2014) but also are independent variables impacting the actual usage behavior of sWOM through mediating variables. For example, the ease of contributing sWOM is also an antecedent of individuals to pursue differences or enhance their self-image. The usefulness of sWOM also enables individuals to participate 
in sharing their experiences or knowledge with a desire to present self-images and social images. Therefore, we expect there is a positive relationship between ease of use and usefulness of sWOM contribution with self-enhancement. The following hypothesis can be proposed:

H10: Perceived usefulness has a positive and direct effect on Self-enhancement.

H11: Perceived ease of use has a positive and direct effect on Self-enhancement.

\subsection{7. sWOM Contribution Scales}

While the motivations of sWOM generation have been received much attention, the structures of sWOM contribution are the types of behavious which have been rarey examined. Rossmann et. al. (2016) divide eWOM communication into two manifestations in which are there are likes and comments about the content posted on an online platform. He states that two types of eWOM engagement benefit for different customer needs and stresses the future research should validate these types toward the differential utilization for information processing purposes. "Comments" or "Posts" activities allow the contributors to express the various sets of emotional and rational which require senders to take more effort and information handling than "Like" (Rossmann et. al., 2016; Becker \& Lee, 2019).

In addition, Dolan et. al. (2019) have identified the contribution sWOM behavior as a moderate level of positivity. He argues that users actively make positive contributions to existing SNSs by "Liking" and "Sharing" brand-related content to their social media profiles. Within the paper, Dolan et. al. (2019) have a limitation in examining the relationship between actions "Liking" and "Sharing". Based on the literature review, two significant limitations should be extended to develop the conceptual differences between these types of contributions. Drawing on the critical social media measurements, we adopt the degree of the contribution activities on two main levels, from the basic level (named Exposure, e.g. being a fan on Facebook or subscribing a channel on YouTube) to the higher level (called Engagement - creation activities e.g. writing, sharing or commenting). sWOM contribution activities must therefore be designed in two constructs where type of exposure has a positive relationship with positive engagement. We suggest the following hypothesis:

H12: Exposure activities have a positive direct effect on Engagement activities

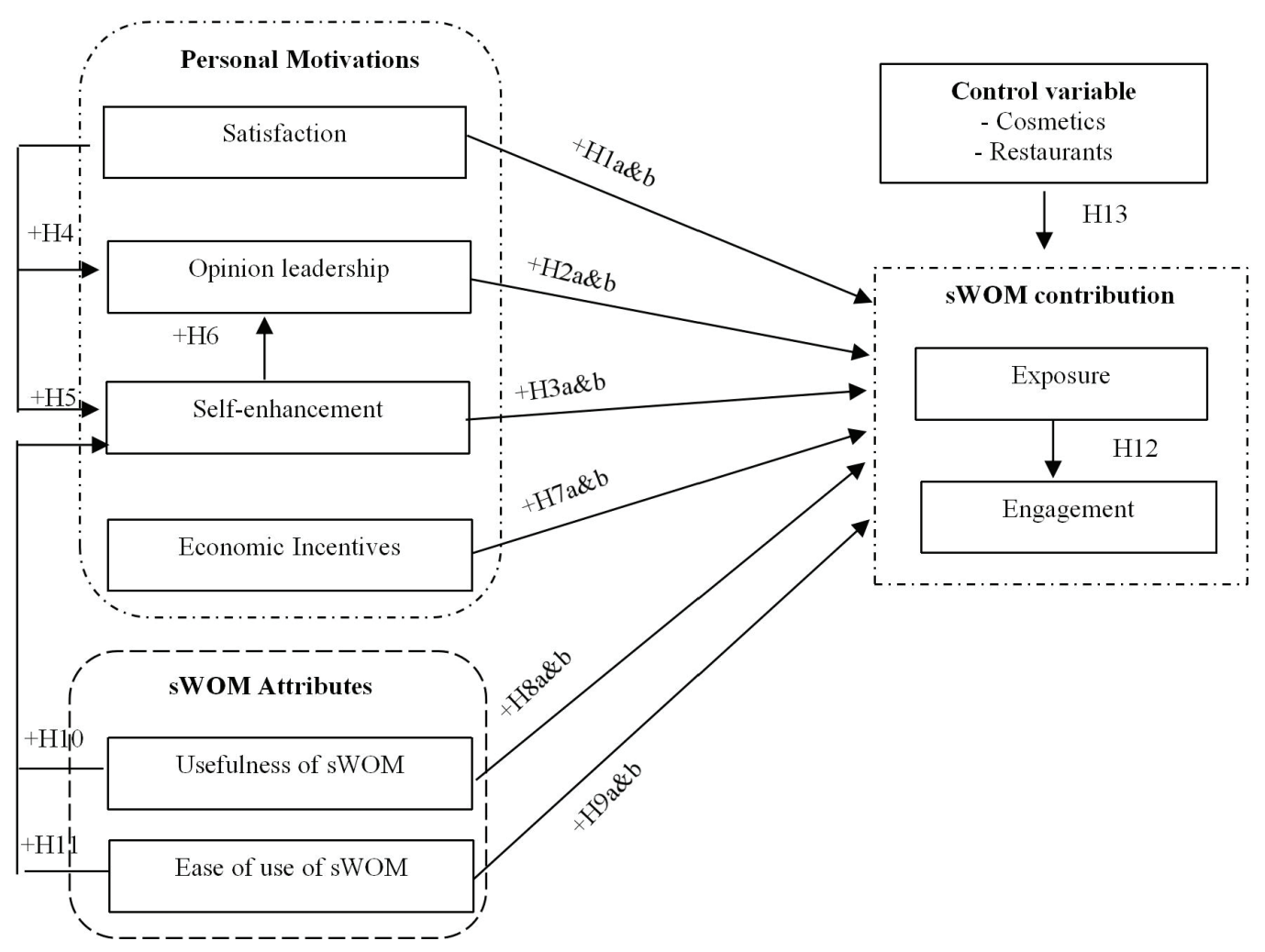

Figure 1: Research model 


\subsubsection{Product versus Service}

The differences between products and services require different advertising strategies (Abernethy, Gray \& Butler, 1997). The evaluation processing of both pre- and postpurchase of services are more difficult for shoppers than products, so personal communication may be more useful for services than products (Pelletier \& Horky, 2015). Recent papers have demonstrated that the important marketing information strategy varies from services to products (Pelletier \& Horky, 2015), consequently, there are differences in motivations for contributing sWOM to a service brand and to a product brand. Rossmann et. al. (2016) highlight a difference between products and services regarding like and comment interactions, however, the selected products and services do not reflect the entire variance and should be retested across other contexts. In Vietnam, topics that people are getting interested in SNSs are cosmetics and restaurants. This study attempts to examine the differences in motivations of sWOM contribution behavior among the online communities of cosmetics and restaurants.

H13: Motivations of sWOM contribution to products and services are likely different

\section{Methodology}

Most of the questionnaire scales have been designed containing some items previously validated and others are developed for the current paper. The measurement items put in the model have been taken from previous studies. To measure these items, a five-point Likert scale was used, ranging from $1=$ strongly disagree to 5 $=$ strongly agree. The questionnaire was designed with demographic data (sex, age, income, etc.) and online social interactions (frequency of logging in SNS, daily time spent on SNS, online regular interactions, etc.). The questionnaire is also modified to fit the topics of cosmetics and restaurants.

To reach the potential respondents, we collect data through a virtual snowball sampling method on Facebook. The reason for selecting Facebook is because it is reported as an SNS accounting for the majority of user-profiles in Vietnam (Kemp, 2020). All respondents are required to be experienced users of the SNS. Finally, a total sample of 904 valid respondents was collected, 465 of cosmetic customers, and 439 of restaurant guests (Table 1).

Table 1: Demographic characteristics

\begin{tabular}{|c|c|c|c|c|}
\hline \multirow[b]{2}{*}{ Gender } & \multicolumn{2}{|c|}{ Cosmetics (465 samples) } & \multicolumn{2}{|c|}{ Restaurants (439 samples) } \\
\hline & & & & \\
\hline Male & 51 & $11.0 \%$ & 147 & $33.5 \%$ \\
\hline Female & 414 & $89.0 \%$ & 292 & $66.5 \%$ \\
\hline \multicolumn{5}{|l|}{ Age } \\
\hline $18-25$ years old & 150 & $32.3 \%$ & 142 & $32.3 \%$ \\
\hline 26-35 years old & 199 & $42.8 \%$ & 187 & $42.6 \%$ \\
\hline $36-45$ years old & 116 & $24.9 \%$ & 110 & $25.1 \%$ \\
\hline \multicolumn{5}{|c|}{ Frequency of SNS usage (per day) } \\
\hline $1-3$ times & 23 & $5.0 \%$ & 23 & $5.2 \%$ \\
\hline $3-5$ times & 125 & $26,9 \%$ & 121 & $27.6 \%$ \\
\hline Above 5 times & 317 & $68.1 \%$ & 295 & $67.2 \%$ \\
\hline \multicolumn{5}{|c|}{ Time spent daily on SNS } \\
\hline Under 1 hour & 152 & $32.7 \%$ & 140 & $31.9 \%$ \\
\hline $1-3$ hours & 184 & $39.6 \%$ & 180 & $41.0 \%$ \\
\hline $3-5$ hours & 58 & $12.5 \%$ & 56 & $12.8 \%$ \\
\hline Always active & 71 & $15.2 \%$ & 63 & $14.35 \%$ \\
\hline \multicolumn{5}{|c|}{ Online social interactions } \\
\hline Comments & 333 & $71.6 \%$ & 309 & $70.4 \%$ \\
\hline Forward & 208 & $44.7 \%$ & 192 & $43.7 \%$ \\
\hline Share & 312 & $67.0 \%$ & 292 & $66.5 \%$ \\
\hline Like & 381 & $81.9 \%$ & 361 & $82.2 \%$ \\
\hline View & 422 & $90.8 \%$ & 400 & $91.1 \%$ \\
\hline
\end{tabular}


The research model used here has been examined using the structural equation modeling (SEM) method and has been combined with SPSS. In particular, this study uses SEM 20.0 software for conducting confirmatory factor analysis (CFA), validating the proposed hypotheses and testing the multigroup analysis.

\section{Data Analysis and Results}

\subsection{Measurement Model}

Confirmatory factor analysis (CFA) was performed to evaluate the validity of the items and the eight factors. The validity of constructs is evaluated through two criteria: convergent validity and discriminant validity. Convergent validity results are shown in Table 2 which are three underlying standards: the factor loadings, the average variance extracted (AVE), and composite reliability (CR) are shown in Table 2. Most factor loadings for all items are large than 0.7, ranged from 0.707 to .949. Each AVE loads from 0.506 to 0.819 , recommended .5 benchmark. Thus, all scales are of convergent validity (Hair, Anderson, Babin \& Black, 2010) (see Table 2).

Discriminant validity is evaluated based on a comparison of the square root of AVE and factor correlation coefficients. As shown in Table 3, the square root of the AVE of each construct is loaded on the diagonal of the table and is in italic. Each factor has a satisfying degree of discriminant validity because the square root of its AVE is greater than the correlation coefficients with other factors. Thus, the results of the measurement model indicate the reliability and validity of constructs in our model, which support the further examination of the hypothesized effects in the research model (see Table 3).

\subsection{Structural Model}

The structural equation modeling (SEM) is proceeded to test the proposed hypotheses. The final measurement model shows $(\chi 2=2769.288, \mathrm{df}=716$; TLI $=0.905, \mathrm{CFI}=0.912$ and RMSEA $=0.056$ ) that there is a good fit of data to the proposed model. The results of the structural model with path coefficients for significant relationships are presented in Table 4.

Table 4 summarizes the results of hypothesis testing. In other words, Satisfaction, Opinion leadership, Selfenhancement, Economic incentives, Usefulness of sWOM, and Ease of use of sWOM played a key factor in influencing sWOM contribution behavior on SNS in Vietnam context. Besides, The Self-enhancement and sWOM - Exposure (H3a); Economic incentives and sWOM - Engagement (H7b); Usefulness of sWOM and sWOM - Engagement (H8b); and Ease of use of sWOM and sWOM - Engagement (H9b) do not support the expected relationship (see Table 4).

\subsection{Multigroup Test}

Table 5 shows the results of the multigroup analysis. Similar to the results in the total samples, the multigroup test shows that there are no significant relationships between Economic incentives, Usefulness of sWOM and Ease of use of sWOM with Engagement, and Self-enhancement with Exposure in any of the two groups. However, the path from Usefulness of sWOM and Ease of use of sWOM to Propensity to Self-enhancement, which was moderately strong in the cosmetic industry, was non-significant in the Restaurant industry. The level of Economic incentives seems to have a somewhat different influence between the two generations. In particular, cosmetic customers are motivated by a reward to Like a page but is not true in the case of a restaurant guest (see Table 5).

\section{Discussion and Conclusion}

For deep understand the sWOM contribution behavior on a specific SNS, the present study has used the motivation theory and TAM model to develop a research model. Our findings identified that satisfaction, opinion leadership, selfenhancement, economic incentives, and sWOM attributes were all significant drivers of sWOM contribution. These findings are consistent with recent researchers' predictions concerning the role of drivers in determining sWOM contribution behavior (Ma et. al., 2014; Kim et. al., 2015; Hennig-Thurau et. al., 2004; Casaló, et. al., 2017; Doma et. al., 2015). The results allow us to offer novel contributions to this interesting topic.

Most importantly, our findings shed some light on the following: (1) There is a strong effect of customer satisfaction on sWOM contribution which has been rarely tested. Specifically, this empirical analysis discovers that customers are more likely to contribute promotional messages within their social networks since they are satisfied with a product or service; (2) sWOM contribution scale exists in two structures (Exposure and Engagement) and affects each other. Individuals inherently can do various social interactions, for example, like and subscribe to a page, share and discuss information about their lives, news, experiences, and so on. Indeed, with supportive tools and a multimedia mix of words, photos, and videos facilitates the contribution process. The contribution behavior is categorized into two types which are related to each other. This finding is different from previous studies that examined the contribution scale in one construct (Kim et. al., 2015; Casaló et. al., 2017; Gvili \& Levy, 2018; Ananda et. al., 2019). (3) This study combines two groups of personal motivation and TAM in a research model; and (4) We examine how differences in motivations of contributing sWOM between a specified service and product that few studies have examined. 
Table 2: Measurement Items

\begin{tabular}{|c|c|c|}
\hline Scale Items & Factor Loading & Source \\
\hline \multicolumn{3}{|l|}{ Satisfaction $(\mathrm{CR}=0.916 ; \mathrm{AVE}=0.687)$} \\
\hline SAT1: ..make the right decision choosing... & 0.723 & \multirow{5}{*}{$\begin{array}{l}\text { Serra-Cantallops } \\
\text { et. al. (2018) }\end{array}$} \\
\hline SAT2: ....satisfied with... & 0.876 & \\
\hline SAT3:... satisfies my needs & 0.949 & \\
\hline SAT4: ...enjoyed... & 0.883 & \\
\hline SAT5: My choice to... a wise one & 0.810 & \\
\hline \multicolumn{2}{|l|}{ Opinion Leadership $(\mathrm{CR}=0.881 ; \mathrm{AVE}=0.597)$} & \\
\hline OL1: ....to influence other people & 0.777 & \multirow{5}{*}{ Ma et. al. (2014) } \\
\hline OL2: ... improves my status & 0.841 & \\
\hline OL3:... regard me as a leader in & 0.859 & \\
\hline OL4:... improve my reputation & 0.783 & \\
\hline OL5:...regard me as a good online source of... & 0.776 & \\
\hline \multicolumn{2}{|l|}{ Self-enhancement $(C R=0.906 ;$ AVE $=0.581)$} & \\
\hline SE1: ...let friends know who I am & 0.795 & \multirow{7}{*}{ Kim et. al. (2015) } \\
\hline SE2:...get impression from friends & 0.785 & \\
\hline SE3: ....enhance my image... & 0.807 & \\
\hline SE4:... gain attention.... & 0.804 & \\
\hline SE5: ... assert superiority... & 0.723 & \\
\hline SE6: ..the kind of person I want to be... & 0.765 & \\
\hline SE7: ...value in followers' eyes & 0.757 & \\
\hline \multicolumn{2}{|l|}{ Economic Incentives $(C R=0.926$ AVE $=0.758)$} & \\
\hline El1: ... receive a reward... & 0.864 & \multirow{4}{*}{$\begin{array}{l}\text { Hennig-Thurau } \\
\text { et. al. (2004) }\end{array}$} \\
\hline EI2: ... economic incentives... & 0.917 & \\
\hline EI3: ....financial benefits.... & 0.894 & \\
\hline El4: ... bonuses... & 0.850 & \\
\hline \multicolumn{2}{|l|}{ Perceived Usefulness (CR $=0.854$ AVE $=0.539)$} & \\
\hline PU1: ....useful suggestions about... & 0.788 & \multirow{5}{*}{$\begin{array}{l}\text { Casaló et. al. } \\
(2017)\end{array}$} \\
\hline PU2:....new idea about.... & 0.759 & \\
\hline PU3: ...improve productivity... & 0.831 & \\
\hline PU4:...improve performance... & 0.788 & \\
\hline PU5:....... is useful. & 0.747 & \\
\hline \multicolumn{2}{|l|}{ Perceived Ease of Use $(\mathrm{CR}=0.803$ AVE $=0.506)$} & \\
\hline PEU1:... not complicate to... & 0.765 & \multirow{4}{*}{$\begin{array}{l}\text { Doma et. al. } \\
(2015)\end{array}$} \\
\hline PEU2:.... without effort... & 0.839 & \\
\hline PEU3:... easy to do what I want... & 0.835 & \\
\hline PEU4:... anytime and anywhere.... & 0.707 & \\
\hline \multicolumn{2}{|l|}{ Exposure $(\mathrm{CR}=0.914$ AVE $=0.819)$} & \multirow{5}{*}{$\begin{array}{l}\text { Kim et. al. (2015); } \\
\text { Casaló et. al. } \\
(2017)\end{array}$} \\
\hline EXP1: ...become a fan.... & 0.900 & \\
\hline EXP2:...save to a favourable list & 0.838 & \\
\hline EXP3:...follow... & 0.919 & \\
\hline EXP4:...view... & 0.838 & \\
\hline \multicolumn{2}{|l|}{ Engagement $(\mathrm{CR}=0.891 \mathrm{AVE}=0.577)$} & \multirow{7}{*}{$\begin{array}{l}\text { Gvili \& Levy } \\
\text { (2018); Ananda et. } \\
\text { al. (2019) }\end{array}$} \\
\hline ENG1: ...forward... to my friend list & 0.830 & \\
\hline ENG2: ....share.... & 0.744 & \\
\hline ENG3: ....upload photos... & 0.770 & \\
\hline ENG4: ....upload videos... & 0.815 & \\
\hline ENG5: ...comment... & 0.819 & \\
\hline ENG6:... recommend... & 0.781 & \\
\hline
\end{tabular}


Table 3: Correlation matrix (CFA results)

\begin{tabular}{|c|c|c|c|c|c|c|c|c|}
\hline & SAT & OL & SE & El & PU & PEU & EX & EN \\
\hline Satisfaction (SAT) & 0.829 & & & & & & & \\
\hline Opinion Leadership (OL) & 0.462 & 0.773 & & & & & & \\
\hline Self-enhancement (SE) & 0.388 & 0.646 & 0.762 & & & & & \\
\hline Economic Incentives (El) & 0.415 & 0.532 & 0.598 & $0.87)$ & & & & \\
\hline Perceived Usefulness (PU) & 0.532 & 0.392 & 0.310 & 0.241 & $0.73)$ & & & \\
\hline Perceived Ease of Use (EU) & 0.158 & 0.264 & 0.129 & 0.137 & 0.131 & 0.711 & & \\
\hline Exposure (EX) & 0.603 & 0.447 & 0.314 & 0.351 & 0.509 & 0.203 & $0.90)$ & \\
\hline Engagement (EN) & 0.520 & 0.519 & 0.557 & 0.390 & 0.418 & 0.149 & 0.531 & 0.760 \\
\hline
\end{tabular}

Table 4: Results of hypothesis testing

\begin{tabular}{|c|c|c|c|c|c|c|}
\hline \multicolumn{4}{|c|}{ Hypotheses } & \multirow{2}{*}{$\begin{array}{c}\begin{array}{c}\text { Path } \\
\text { coefficient }\end{array} \\
0.473\end{array}$} & \multirow{2}{*}{$\begin{array}{c}\text { S.E. } \\
0.053\end{array}$} & \multirow{2}{*}{$\begin{array}{c}\text { Supported? } \\
\text { Yes }\end{array}$} \\
\hline $\mathrm{H} 1 \mathrm{a}$ & Satisfaction & $\rightarrow$ & sWOM - Exposure & & & \\
\hline $\mathrm{H} 1 \mathrm{~b}$ & Satisfaction & $\rightarrow$ & sWOM - Engagement & 0.195 & 0.052 & Yes \\
\hline $\mathrm{H} 2 \mathrm{a}$ & Opinion leadership & $\rightarrow$ & sWOM - Exposure & 0.176 & 0.046 & Yes \\
\hline $\mathrm{H} 2 \mathrm{~b}$ & Opinion leadership & $\rightarrow$ & sWOM - Engagement & 0.091 & 0.044 & Yes \\
\hline $\mathrm{H} 3 \mathrm{a}$ & Self-enhancement & $\rightarrow$ & sWOM - Exposure & 0.070 & 0.039 & Not \\
\hline $\mathrm{H} 3 \mathrm{~b}$ & Self-enhancement & $\rightarrow$ & sWOM- Engagement & 0.318 & 0.039 & Yes \\
\hline $\mathrm{H} 4$ & Satisfaction & $\rightarrow$ & Opinion leadership & 0.297 & 0.039 & Yes \\
\hline H5 & Satisfaction & $\rightarrow$ & Self-enhancement & 0.402 & 0.054 & Yes \\
\hline $\mathrm{H} 6$ & Self-enhancement & $\rightarrow$ & Opinion leadership & 0.490 & 0.035 & Yes \\
\hline $\mathrm{H} 7 \mathrm{a}$ & Economic incentives & $\rightarrow$ & sWOM - Exposure & 0.058 & 0.027 & Yes \\
\hline $\mathrm{H} 7 \mathrm{~b}$ & Economic incentives & $\rightarrow$ & sWOM - Engagement & -0.024 & 0.025 & Not \\
\hline $\mathrm{H} 8 \mathrm{a}$ & Usefulness of sWOM & $\rightarrow$ & sWOM - Exposure & 0.306 & 0.050 & Yes \\
\hline $\mathrm{H} 8 \mathrm{~b}$ & Usefulness of sWOM & $\rightarrow$ & sWOM - Engagement & 0.074 & 0.047 & Not \\
\hline $\mathrm{H} 9 \mathrm{a}$ & Ease of use of sWOM & $\rightarrow$ & sWOM - Exposure & 0.086 & 0.039 & Yes \\
\hline $\mathrm{H} 9 \mathrm{~b}$ & Ease of use of sWOM & $\rightarrow$ & sWOM - Engagement & -0.007 & 0.037 & Not \\
\hline $\mathrm{H} 10$ & Usefulness of sWOM & $\rightarrow$ & Self-enhancement & 0.186 & 0.059 & Yes \\
\hline $\mathrm{H} 11$ & Ease of use of sWOM & $\rightarrow$ & Self-enhancement & 0.101 & 0.047 & Yes \\
\hline $\mathrm{H} 12$ & sWOM - Exposure & $\rightarrow$ & sWOM - Engagement & 0.248 & 0.039 & Yes \\
\hline
\end{tabular}

Notes: $p<0.05$

Table 5: Multigroup analysis: product and service

\begin{tabular}{|l|l|l|c|c|c|c|}
\hline \multicolumn{2}{|c|}{ Path } & \multicolumn{2}{c|}{ Cosmetics } & \multicolumn{2}{c|}{ Restaurants } \\
\cline { 3 - 7 } & $\rightarrow$ & Self-enhancement & 0.204 & 0.009 & 0.166 \\
\hline Usefulness of sWOM & $\rightarrow$ & 0.137 & 0.031 & 0.056 \\
\hline Ease of use of sWOM & $\rightarrow$ & Self-enhancement & 0.071 & 0.037 & 0.041 & 0.327 \\
\hline Economic incentives & $\rightarrow$ & sWOM-Exposure & Path coefficients & P \\
\hline
\end{tabular}




\subsection{Theoretical Implications}

Very few researchers have conducted an analysis of the sWOM contribution behavior by combining personal motivations with characteristics of the technology. Previous researches have focused on a single touchpoint, particularly on rational and emotional motivations and we found that customers who contribute sWOM on SNSs are encouraged by a complex set of motivations. Our findings have proven that those drivers are potential determinants of exposure and engagement activities in both the restaurant services and specific cosmetic products. Hence, the conceptual model proposed in this study contributes to the existing literature on better understanding the drivers of sWOM contribution.

We contribute the literature to investigate the driving motivations forward sWOM interactions, specifically customer satisfaction. Although previous studies have recognized various underlying drivers of customer engagement behind the emotional experiences (SerraCantallops, et. al., 2018), few recent studies have examined customer satisfaction as a factor to guaranty the contribution of positive sWOM. This present research also makes an important theoretical contribution in terms of evaluating the relationship between customer satisfaction and opinion leadership or self-enhancement. Notably, our results have suggested a conceptual construct of exposure and engagement behaviors that can apply to the SNS scenario draw these scales from the previous studies to shed some important insights regarding online customer contribution.

\subsection{Managerial Implications}

The positive sWOM is extremely valuable for both service and product companies because it not only impacts positively on the company's reputation but also facilitates in retaining the existing customers and attracting new customers in a very competitive market. The study has several managerial contributions for digital managers who do business in both tangible and intangible products. First, in preparing social media-based advertising campaigns, digital marketers may carefully choose a set of driving motivations for contributing positive sWOM messages among target shoppers, especially satisfied customers. Based on proper customer relationship policies, companies can do a great job of retaining the customers in an effective way, these customers with their positive comments will push the company at the top positions in the online ranking board. Marketing managers could encourage their customers to spread sWOM communication by developing stronger relationships with satisfied consumers who provide proper solutions to increase the probability of positive reviews on social media platforms.
According to our results, companies should pay attention to opinion leadership customers to facilitate online marketing programs. Online opinion leaders have a large network of followers and fans, so companies can invite opinion leaders to test their products and encourage them to generate positive eWOM. At the same time, managers can offer economic incentives for online opinion leaders to discuss their brands more frequently. In other words, organizations could consider opinion leaders as the strategic tools in generating positive sWOM on social media. With collectivistic cultures, Vietnamese customers likely to reflect individual identity by presenting their own experiences to an online community is a method to stimulate positive sWOM contribution. Therefore, digital managers may integrate their marketing strategies with self-image values that appeal to the target customers. For example, restaurant managers can encourage their guests to post unique photos of the dishes and artful foods, cosmetic companies can ask users to make an in-person demonstration. Besides, the perceived usefulness and ease of use are potential antecedents of various exposure activities with a brand on SNSs. Marketing managers consider uploading content in line with what consumers seek and encourage followers and fans to share or/and forward to others. Companies should also provide comfortable feelings for their fans by improving and carefully designing their pages.

\section{Limitations and Future Research}

Although this study provides some interesting motivations for positive sWOM contribution, future research needs to solve some limitations. First, this study examined the motives of contributing positive sWOM only, while negative sWOM has received much attention in recent years Zhang, Omran \& Cobanoglu, 2017). The emergence of social media allows customers to share their thoughts about satisfactory and unsatisfactory experiences, future research should discover as to what are the differences in the driving motives which leads to positive and negative sWOM contribution. Our participants were Vietnamese who follow a collective culture and and may differ on an individual level. Future researches can explore these motivations from cross-cultural perspectives to fill this gap. Finally, technology is always advancing, and so the continued model which can be refined by incorporating new constructs.

\section{References}

Abernethy, A. M., Gray, J. I., \& Butler, D. D. (1997). Radio advertising information strategy: Differences between services and products. Journal of Services Marketing, 11(5), 344-357.

Ananda, A. S., Hernández-García, Á., Acquila-Natale, E., \& Lamberti, L. (2019). What makes fashion consumers "click"? 
Generation of eWoM engagement in social media. Asia Pacific Journal of Marketing and Logistics, 31(2), 398-418.

Balaji, M. S., Khong, K. W., \& Chong, A. Y. L. (2016). Determinants of negative word-of-mouth communication using social networking sites. Information \& Management, 53(4), 528-540.

Becker, K., \& Lee, J. W. (2019). Organizational usage of social media for corporate reputation management. Journal of Asian Finance, Economics and Business, 6(1), 231-240. http://doi. org/10.13106/jafeb.2019.vol6.no1.231

Belarmino, A. M., \& Koh, Y. (2018). How E-WOM motivations vary by hotel review website. International Journal of Contemporary Hospitality Management, 30(8), 2730-2751.

Blau, P.M. (1964) Exchange and Power in Social Life. Piscataway, NJ: Transaction Publishers.

Bronner, F., \& De Hoog, R. (2011). Vacationers and eWOM: Who posts, and why, where, and what? Journal of Travel Research, 50(1), 15-26.

Casaló, L. V., Flavián, C., \& Ibáñez-Sánchez, S. (2017). Antecedents of consumer intention to follow and recommend an Instagram account. Online Information Review, 41(7), 1046-1063

Davis, F. D. (1989). Perceived usefulness, perceived ease of use, and user acceptance of information technology. MIS Quarterly, 13(3), 319-340. DOI: $10.2307 / 249008$

Dolan, R., Conduit, J., Frethey-Bentham, C., Fahy, J., \& Goodman, S. (2019). Social media engagement behavior: A framework for engaging customers through social media content. European Journal of Marketing. 53(10), 2213-2243.

Doma, S. S., Elaref, N.A., \& Elnaga, M. A. (2015). Factors Affecting Electronic Word-of-Mouth on Social Networking Websites in Egypt: An Application of the Technology Acceptance Model. Journal of Internet Social Networking \& Virtual Communities, 2015, a1-31.

Eastman, J. K., Iyer, R., Liao-Troth, S., Williams, D. F., \& Griffin, M. (2014). The role of involvement on millennials' mobile technology behaviors: The moderating impact of status consumption, innovation, and opinion leadership. Journal of Marketing Theory and Practice, 22(4), 455-470

Eisingerich, A. B., Chun, H. H., Liu, Y., Jia, H. M., \& Bell, S. J. (2015). Why recommend a brand face-to-face but not on Facebook? How word-of-mouth on online social sites differs from traditional word-of-mouth. Journal of Consumer Psychology, 25(1), 120-128.

Flynn, L. R., Goldsmith, R. E., \& Eastman, J. K. (1996). Opinion leaders and opinion seekers: Two new measurement scales. Journal of the Academy of Marketing Science, 24(2), 137. https://doi.org/10.1177/0092070396242004

Gvili, Y., \& Levy, S. (2018). Consumer engagement with eWOM on social media: The role of social capital. Online Information Review. 42(4), 482-505

Hair, J. F., Anderson, R. E., Babin, B. J., \& Black, W. C. (2010). Multivariate data analysis: A global perspective (7th ed.). Upper Saddle River, NJ: Pearson.
Han, J. H. (2020). The Effects of Personality Traits on Subjective Well-being and Behavioral Intention Associated with Serious Leisure Experiences. Journal of Asian Finance, Economics, and Business, 7(5), 167-176. https://doi.org/10.13106/ jafeb.2020.vol7.no5.167

Hennig-Thurau, T., Gwinner, K. P., Walsh, G., \& Gremler, D. D. (2004). Electronic word-of-mouth via consumer-opinion platforms: What motivates consumers to articulate themselves on the internet? Journal of Interactive Marketing, 18(1), 38-52.

Jungnickel, K. (2018). New methods of measuring opinion leadership: A systematic, interdisciplinary literature analysis. International Journal of Communication, 12, 2702-2724.

Kim, D., Jang, S., \& Adler, H. (2015). What drives café customers to spread eWOM?: Examining self-relevant value, quality value, and opinion leadership. International Journal of Contemporary Hospitality Management, 27(2), 261-282.

Kemp, Simon (2020). Digital 2020 reports. Wearesocial Blog. Retrieved July 12, 2020 from https://wearesocial.com/ blog/2020/01/digital-2020-3-8-billion-people-use-socialmedia

Lee, J. W. (2017). Critical factors affecting consumer acceptance of online health communication: An application of service quality models. Journal of Asian Finance, Economics and Business, 4(3), 85-94. http://dx.doi.org/10.13106/jafeb.2017.vol4.no3.85

Litvin, S. W., Goldsmith, R. E., \& Pan, B. (2008). Electronic wordof-mouth in hospitality and tourism management. Tourism Management, 29(3), 458-468.

Lyons, B., \& Henderson, K. (2005). Opinion leadership in a computer-mediated environment. Journal of Consumer Behaviour: An International Research Review, 4(5), 319-329.

Ma, L., Lee, C. S., \& Goh, D. H. L. (2014). Understanding news sharing in social media. Online Information Review, 38(5), 598-615.

Muntinga, D. G., Moorman, M., \& Smit, E. G. (2011). Introducing COBRAs: Exploring motivations for brand-related social media use. International Journal of Advertising, 30(1), 13-46.

Nguyen, H. M., Dang, L. A. T., \& Ngo, T. T. (2019). The Effect of Local Foods on Tourists' Recommendations and Revisit Intentions: The Case in Ho Chi Minh City, Vietnam. Journal of Asian Finance, Economics and Business, 6(3), 215-223. https:// doi.org/10.13106/jafeb.2019.vol6.no3.215

Oliveira, B., \& Casais, B. (2019). The importance of user-generated photos in restaurant selection. Journal of Hospitality and Tourism Technology, 10(1), 2-14.

Park, S. Y., \& Kang, Y. J. (2013). What's going on in SNS and social commerce?: Qualitative approaches to narcissism, impression management, and e-WOM behavior of consumers. Journal of Global Scholars of Marketing Science, 23(4), 460-472.

Pelletier, M. J., \& Horky, A. B. (2015). Exploring the Facebook Like: A product and service perspective. Journal of Research in Interactive Marketing, 9(4), 337-354. 
Rauniar, R., Rawski, G., Yang, J., \& Johnson, B. (2014). Technology acceptance model (TAM) and social media usage: An empirical study on Facebook. Journal of Enterprise Information Management, 27(1) 6-30

Rossmann, A., Ranjan, K. R., \& Sugathan, P. (2016). Drivers of user engagement in eWoM communication. Journal of Services Marketing, 30(5), 541-553.

Ruiz-Mafe, C., Martí-Parreño, J., \& Sanz-Blas, S. (2014). Key drivers of consumer loyalty to Facebook fan pages. Online Information Review, 38(3), 362-380.

Seol, S., Lee, H., Yu, J., \& Zo, H. (2016). Continuance usage of corporate SNS pages: A communicative ecology perspective. Information \& Management, 53(6), 740-751.

Serra-Cantallops, A., Ramon-Cardona, J., \& Salvi, F. (2018). The impact of positive emotional experiences on eWOM generation and loyalty. Spanish Journal of Marketing-ESIC. 22(2), 142162.

Styvén, M. E., \& Foster, T. (2018). Who am I if you can't see me? The "self" of young travellers as driver of eWOM in social media. Journal of Tourism Futures, 4(1), 80-92.

Summers, J. O. (1970). The identity of women's clothing fashion opinion leaders. Journal of Marketing Research, 7(2), 178-185.
Sundaram, D. S., Mitra, K., \& Webster, C. (1998). Word-ofmouth communications: A motivational analysis. ACR North American Advances, 25(1), 527-531

Sung, H. Y., Kim, J. J., \& Youn, M. K. (2014). A Study upon Effects of Family Restaurant Consumption Values upon Satisfaction, Reliability and Behavioural Intentions in Korea: Focused on College Students at Metropolitan Area. Journal of Asian Finance, Economics and Business, 1(4), 29-37. https://doi. org/10.13106/jafeb.2014.vol1.no4.29.

Tan, W. K., \& Lee, B. Y. (2019). Investigation of electronic-wordof-mouth on online social networking sites written by authors with commercial interest. Online Information Review. 43(3), 462-480.

Tsao, W. Y. (2019). Building the long bridge between visitors and customers through online general reviews. Online Information Review, 43(2), 201-218.

Yang, F. X. (2017). Effects of restaurant satisfaction and knowledge sharing motivation on eWOM intentions: The moderating role of technology acceptance factors. Journal of Hospitality \& Tourism Research, 41(1), 93-127.

Zhang, T. C., Omran, B. A., \& Cobanoglu, C. (2017). Generation Y's positive and negative eWOM: Use of social media and mobile technology. International Journal of Contemporary Hospitality Management, 29(2), 732-761. 